\title{
MARCADOS PELO CRIME: OS DESAFIOS ENFRENTADOS NO PRO- CESSO DE REINSERÇÃO SOCIAL DE PESSOAS QUE CUMPRIRAM PENA EM REGIME FECHADO
}

MARKED BY THE CRIME: THE CHALLENGES FACED IN THE PROCESS OF SOCIAL REINTEGRATION OF PEOPLE WHO FULFILLED PENALTY IN CLOSED REGIME

\section{Jhennyfer Jully Mutz', Alexandre Cardoso Aranzedo²}

RECEBIDO EM: 19/12/2018 | ACEITO EM: 12/03/2020

DOI: $10.5902 / 2317175836119$

\section{RESUMO}

A pesquisa teve como objetivo identificar os desafios enfrentados no processo de ressocialização após a experiência de cumprimento de pena em regime fechado, bem como identificar possíveis preconceitos e tipos de violência sofridos, além de verificar a participação familiar no auxílio dessa busca. Sendo assim, é uma pesquisa qualitativa descritiva, em que foram entrevistados seis homens entre 23 e 37 anos que cumpriram pena em regime fechado em alguns presídios no Espírito Santo, cujos resultados foram categorizados por meio da Análise de Conteúdo e interpretados a partir de conceitos da psicologia social. Com isto, obteve-se como resultados os principais fatores que dificultam a ressocialização dessas pessoas como violência física no ato da prisão e durante o cumprimento da pena, diferentes tipos de preconceitos sofridos após a liberdade desses sujeitos tais como estereotipagem, segregação, invisibilidade social e categorização, além da falta de oportunidade na vida fora do crime versus oportunidades de ascensão através da criminalidade aliada ao contexto de dificuldade financeira. Além disso, notou-se que a família é a instituição social que mais apoia os indivíduos na busca da reinserção social, além de ser o grupo que mantém constante presença na vida deles. Contudo, observa-se a necessidade de mudanças sociais na cultura do crime.

Palavras-chave: Reinserção social; Violência; Preconceitos; Família.

1 Aluna do $10^{\circ}$ período do curso de Psicologia da Católica de Vitória Centro Universitário. Católica de Vitória Centro Universitário.

2 Graduado em Psicologia pela Universidade Federal do Espírito Santo (2003). Mestre em Psicologia pela Universidade Federal do Espírito Santo (2006) e Doutor em Psicologia pela Universidade Federal do Espírito Santo (2007 - 2012). Atualmente é Coordenador e Docente do Curso de Psicologia da Católica de Vitória Centro Universitário. 
MARCADOS PELO CRIME: OS DESAFIOS ENFRENTADOS NO PROCESSO DE REINSERÇÃO SOCIAL DE PESSOAS QUE CUMPRIRAM PENA EM REGIME FECHADO

\begin{abstract}
The research aimed to identify the challenges faced in the process of resocialization after the experience of compliance with sentence in a closed regime. As well as, to identify possible prejudices and types of violence suffered, besides verifying the family participation in the aid of this search. Thus, it is a descriptive qualitative research, where six men between 23 and 37 years old who were sentenced to prison sentences in a few Espirito Santo prisons were interviewed, whose results were categorized through Content Analysis and interpreted from concepts of social psychology. As a result, the main factors that hinder the re-socialization of these individuals, such as physical violence in the act of imprisonment and during the execution of the sentence, have been obtained, different types of prejudices suffered after the freedom of these subjects such as stereotyping, segregation, social invisibility and categorization, as well as the lack of opportunity in life outside of crime versus opportunities for ascent through crime allied with the context of financial difficulty. In addition, it was noted that the family is the social institution that most supports individuals in the search for social reintegration, besides being the group that maintains a constant presence in their lives. However, there is a need for social changes in the culture of crime.

Keywords: Social reinsertion; Violence; Prejudices; Family.
\end{abstract}

\title{
1 Introdução
}

Comumente as pessoas que cometem crimes são pessoas que "vivem à margem, banidos, segregados, e quando mortos não suscitam questionamento ou responsabilização, como se fossem vidas mortas, mortos-vivos à espera de um fim já conhecido em vida" (SEQUEIRA, 2011).

Não é raro ouvir a famosa frase "Bandido bom é bandido morto! ". Essa frase traz para a sociedade a falsa proposta de "limpeza" da criminalidade por uma via de violência. Contudo, em uma reflexão mais aprofundada, observa-se nisso a busca por caminhos mais fáceis para resolução de problemas sociais, tratando o efeito e não a causa do problema.

Diante do exposto, verifica-se a necessidade da realização desta pesquisa para identificar os desafios encontrados por quem busca essa reinserção social. Além disso, torna-se necessária também para a comunidade científica devido à apresentação de dados importantes para o maior conhecimento do campo da ressocialização de indivíduos que já cumpriram pena em regime fechado, de forma que facilite a reinserção social do sujeito e por consequência diminua-se a criminalidade. Ressalta-se que há delimitação desse estudo qualitativo, cujos resultados não podem ser generalizados devido a princípios que norteiam a psicologia social e as vivências humanas sociais.

O estudo se torna de grande importância para a sociedade, visto que pode auxiliar na reflexão sobre alguns preconceitos enraizados de que o sujeito perde toda sua história de vida que constituiu até o momento em que comete um crime e passa a ser identificado apenas como um "criminoso". E, também, pode auxiliar o entendimento de que um dos caminhos para a redução da criminalidade está na ressocialização desses indivíduos. 
O presente trabalho parte do seguinte problema de pesquisa: quais os desafios enfrentados no processo de ressocialização após a experiência de cumprimento de pena em regime fechado? Por conseguinte, possui o objetivo de identificar possíveis preconceitos e tipos de violência sofridos por esses indivíduos durante a prisão, no cumprimento da pena e após a liberdade, além de conhecer fatores que dificultam a aceitação social do sujeito que busca a ressocialização e, por último, verificar a participação do papel familiar no auxílio em prol da ressocialização.

\section{Referencial teórico}

\subsection{Violência e criminalidade}

A violência é um conceito bem mais amplo do que o ato criminoso. Para Bock, Furtado e Teixeira (2009, p. 330) "a violência é uma produção humana, não se resume ao crime, embora seja sua face mais descarada". Bock, Furtado e Teixeira (2009) ainda trazem a reflexão acerca dos conceitos de agressividade e violência, e salienta a diferença entre ambos.

A agressividade é algo inerente ao ser humano. Pode-se observar uma base para essa afirmativa em Rodrigues, Assmar e Jablonski (2001, p. 213)

Sob a perspectiva biológica, alguns pesquisadores identificaram sistemas neurais tanto em animais quanto em humanos que facilitam a agressão. Segundo eles, quando tais sistemas ativam determinadas áreas do cérebro, a hostilidade aumenta e, quando desativadas, a hostilidade diminui.

O controle social é o que faz com que o ser humano cresça aprendendo a reprimir essa agressividade. E com isto a cultura se torna um instrumento importante para a canalização dessa agressividade, para que ela transforme impulsos destrutivos em algo positivo. (BOCK; FURTADO; TEIXEIRA, 2009).

Pode-se entender violência como "um sintoma social cuja produção é determinada por fatores históricos, econômicos, sociais, culturais, demográficos, psicológicos e outros" (BOCK; FURTADO; TEIXEIRA, 2009, p.331).

Isso afirma o que Sequeira (2011) aponta que a culpabilização da família pela violência ou os atos criminosos de um indivíduo é uma falha reflexão, assim como relata que a sociedade é perversa neste sentido: com o não cumprimento do seu papel social.

Apesar de serem comumente confundidos, violência e criminalidade são conceitos distintos. Embora não haja normas para definição da violência, ela pode ser entendida como atos destinados a algo ou a alguém, que de modo direto ou indireto, Ihe causam danos, sejam eles físicos, materiais ou morais. Logo nem todo ato criminoso pode ser considerado como violência (MICHAUD, 1989). 
MARCADOS PELO CRIME: OS DESAFIOS ENFRENTADOS NO PROCESSO DE REINSERÇÃO SOCIAL DE PESSOAS QUE CUMPRIRAM PENA EM REGIME FECHADO

Por muito tempo houve uma correlação entre pobreza e criminalidade, em que se acreditava que a pobreza desencadeava violência. Atualmente, sabe-se que esta questão é bem mais ampla. Entende-se que a pobreza de fato produz uma vulnerabilidade social para o indivíduo, entretanto, não é um fator determinante para que este sujeito seja violento, tampouco um criminoso em potencial (MICHAUD, 1989; BOCK; FURTADO; TEIXEIRA, 2009).

A violência, apesar de acompanhar a história da humanidade, é algo que causa destruição na sociedade contemporânea. Não é algo inerente ao ser humano, é um evento aprendido, além de ser um instrumento contra os direitos humanos. E para que haja um controle social, existe a punição para os desvios das normas morais (PEQUENO, 2016).

\subsection{A punição e seu contexto histórico}

O ato de punir um indivíduo por um crime cometido é tão antigo quanto o próprio crime em si. O que vem se modulando ao longo do tempo é a forma com que isso se dá. Pode-se observar que em meados do século XVIII a punição se dava através de suplícios, que se baseava numa cena de barbárie em praça pública (pelourinhos). Um circo de horrores a céu aberto (FOUCALT, 2002).

Ainda dentro do século XVIII, porém três décadas mais tarde, nasce a utilização do tempo - um conjunto de normas que regia o regulamento na Casa dos Jovens Detentos em Paris (FOUCALT, 2002). Esse foi o século de grandes modificações e redistribuições da economia do castigo, tanto nos Estados Unidos quanto na Europa. Ao fim desse século também começou uma tendência à extinção do suplício, e com o início do século XIX veio uma organização do castigo de acordo com os indivíduos culpados (FOUCALT, 2002). Com todas essas modificações, Foucalt (2002, p.12) aponta que "a punição pouco a pouco deixou de ser uma cena" e começa a desaparecer o "corpo como alvo principal da repressão penal".

Atualmente há a segregação do preso, porém, não para atingir o objetivo, que teoricamente seria de capacitar esse encarcerado para retorno a vida social de forma que não seja reincidente, mas sim como forma de neutralizar uma parte da população excedente. Bem longe do que deveria propor de fato, a punição forma um novo ser, todavia, por diversas vezes, a partir deste nasce um filho do sistema prisional, alguém que carrega para o resto da vida o que deveria ser apenas um fragmento dela (SEQUEIRA, 2011).

A prisão é um instrumento de segregação social. Sequeira (2011, p. 45) aponta que "desumano é o tratamento penal, como o não lugar que mata o homem em vida". Claramente, a mais evidente é a separação do encarcerado com o restante da sociedade. Mas não só isto. A desconstrução da identidade do sujeito já ocorre quando este adentra o sistema prisional, onde há a retirada de seus objetos pessoais, cortes de cabelos iguais e outros ritos formais para que haja a uniformização dos homens (BARCINSKI; CÚNICO, 2014). 
As prisões atuais do sistema carcerário brasileiro, cuja principal função é a de reeducar o preso para o retorno ao convívio social, passam por dificuldades, proporcionadas por diversos fatores. Com isso, dificulta também o processo de reinserção social (SILVA, 2018).

\subsection{0 processo de reinserção social}

A falha em instituições de controle social, como por exemplo educação e família, pode se tornar um fator que possibilite uma cultura de violência e de criminalidade como forma de sociabilidade. Diante disso, torna-se fundamental que esses indivíduos superem estas culturas por meio do processo de ressocialização. É de extrema importância que, nesse processo, o sujeito reestruture sua personalidade e absorva as normas e valores sociais voltados para o mundo do trabalho (MADEIRA, 2004).

Braga (2014) compreende a reintegração social a partir dos núcleos de oportunidades que o apenado possa a vir receber ao fim de sua pena e por estratégias que permitam a sociedade civil livrar-se da prisão por meio de condições culturais e políticas. Esse processo de ressocialização perpassa pelos pressupostos de trabalho da sociedade no cárcere com a finalidade de diminuir a linha que divide sociedade e prisão; propostas relacionadas à inclusão social; reconhecimento da dignidade dos apenados; participação voluntária dos encarcerados; e readequação da ética desses indivíduos.

Sendo assim, as práticas relacionadas à ressocialização podem, por sua vez, diminuir ou limitar práticas criminais futuras e os possíveis efeitos psíquicos causados pela experiência de viver enclausurado, visto que a privação de liberdade pode causar efeitos psicológicos, e ainda não contribui com a construção da autonomia de identidade do sujeito (Braga, 2014). Com isto, entende-se que "uma nova perspectiva de trabalho deve ser pensada, desvinculada da lógica de prêmio e castigo, não a partir do cárcere, mas apesar dele" (BRAGA, 2014, p. 10).

$\mathrm{O}$ indivíduo que foi encarcerado possui um estigma que pode se perpetuar por toda sua vida. Recomeçar tudo após o cárcere pode significar o enfrentamento a diversos desafios: readaptação aos hábitos e costumes; obtenção de um emprego; enfrentar preconceitos e a marginalização que a sociedade emite; dentre outros (SIQUEIRA; ROSTELATO, 2009).

Além disso, a desatualização da Lei de Execução Penal, a falta de investimentos no sistema carcerário, a superlotação de celas, a corrupção dentro dos presídios e penitenciárias, a falta de condições sanitárias, a ausência de investimento em infraestrutura e recursos humanos só auxilia no fracasso da proposta de ressocialização dos detentos, visto que muitos presos que passam pelo sistema penitenciário voltam à prática de crimes, e por vezes mais graves que o anterior. As prisões atuais, além de não atingirem o objetivo principal, ainda têm se tornado uma escola de criminalidade (OLIVEIRA, et al., 2017). 
MARCADOS PELO CRIME: OS DESAFIOS ENFRENTADOS NO PROCESSO DE REINSERÇÃO SOCIAL DE PESSOAS QUE CUMPRIRAM PENA EM REGIME FECHADO

Nobre e Peixoto (2015) também apontam os problemas carcerários como fatores que levam ao fracasso do processo de ressocialização. Santos e Souza (2013) explicitam que a lógica da ressocialização é contrariada no sistema em que ela deveria ser iniciada, ou seja, o próprio sistema prisional viola os princípios básicos da dignidade humana e que o processo de reinserção social é apenas uma idealização não praticada do sistema prisional brasileiro. Já para Cabral e Medeiros (2014), os fatores que impedem o processo de ressocialização estão relacionados com o preconceito, medo e desrespeito vivenciados durante o cárcere e que acompanham o detento quando retorna ao convívio social.

\subsection{As faces do preconceito}

Entende-se que o preconceito é uma ideia pré-concebida que direciona a um determinado grupo ou um indivíduo o comportamento negativo e/ ou atitude. Esses comportamentos e/ou atitudes não são direcionados apenas aos grupos minoritários, mas a qualquer grupo social (RODRIGUES; ASSMAR; JABLONSKI, 2001).

Como base do preconceito, há o estereótipo que são "crenças sobre características pessoais que atribuímos a indivíduos ou grupos" (RODRIGUES; ASSMAR; JABLONSKI, 2001, p. 150). O estereótipo é uma forma de classificar ou categorizar as pessoas, ou seja, os humanos tendem a poupar energia e tempo quando emitem esse comportamento funcional e, na maioria das vezes, bem equivocado, para não ter que realizar uma análise mais reflexiva toda vez que conhece uma nova pessoa ou grupo (RODRIGUES; ASSMAR; JABLONSKI, 2001).

Contudo, o estereótipo não se resume a essa explicação, pois se assim fosse, à medida que houvesse mais informações, os erros seriam corrigidos e não seriam tão resistentes, quanto ocorre no estereótipo (ÁLVARO; GARRIDO, 2006).

A essa resistência são atribuídos dois motivos:

Em primeiro lugar, a natureza da informação com a qual se contrasta a validade da categorização é diferente no caso do mundo físico e no caso do mundo social. No primeiro caso, a atribuição de um objeto a uma categoria a qual não pertence poderia ser também não adaptativa e, com isso, a pessoa corrigiria os erros cometidos ao receber informações sobre eles. No caso do meio ambiente social, a informação é mais ambígua; além disso, o fato de os estereótipos serem compartilhados faz com que o consenso social sobre eles possa ser utilizado como um critério de validade. Nesse sentido, mera confirmação de que outras pessoas mantêm as mesmas crenças que nós sobre determinados grupos serviria como confirmação de sua adequação (ÁLVARO; GARRIDO, 2006, p. 275).

Existe uma forma de preconceito que se assemelha ao estereótipo: a rotulação. Porém, o rótulo é uma maneira de antecipar o comportamen- 
to que o outro emitirá. Ou seja, uma expectativa em relação ao outro, que não é necessariamente uma expectativa correta, assim como no estereótipo, pode ser uma forma equivocada de "analisar" o outro (RODRIGUES; ASSMAR; JABLONSKI, 2001).

Outra forma de preconceito que pode vir a contaminar as percepções em relação ao outro é via atribuição de causalidade. Que pode ser resumidamente explicada por uma "previsão" sobre os motivos que possam ter levado um indivíduo ou um grupo às determinadas ações (RODRIGUES; ASSMAR; JABLONSKI, 2001).

Se o estereótipo é a sua base cognitiva, os sentimentos negativos em relação a um grupo constituiriam o componente afetivo do preconceito, e as ações, o componente comportamental. Em sua essência, o preconceito é uma atitude: uma pessoa pode desgostar de pessoas de certos grupos e comportar-se de maneira ofensiva para com eles, baseado em uma crença segundo a qual possuem características negativas (RODRIGUES; ASSMAR; JABLONSKI, 2001, p. 162).

A invisibilidade social, outra forma de preconceito, é apontada por Uhlein ( $\mathrm{s} / \mathrm{d}$ ) como um problema social, político e econômico e que é justamente não ser visto, se tornar invisível em seu ambiente natural, ainda que o indivíduo queira ser visto.

Embora as pessoas percebam o preconceito como atitudes hostis, o preconceituoso pode ou não ter tais atos ou comportamentos persecutórios, ou seja, o preconceito é algo que todos possuem, porém nem todos emitem os atos discriminatórios (RODRIGUES; ASSMAR; JABLONSKI, 2001).

A aceitação social é um fator que influencia bastante no sucesso ou fracasso no processo de ressocialização, visto que

Cada demonstração de rejeição ao ex-detento pode significar-lhe um incentivo ao ócio e continuidade na prática delituosa, tudo o que se faz imprescindível é mesmo o apoio e confiança a serem demonstrados, para que possa vir a motivar o ex-detento a continuar sua vida, distante da prática delituosa (SIQUEIRA; ROSTELATO, 2009, p. 119).

Quando o encarcerado retorna à sociedade, esta torna o convívio um tanto penoso, pois esse indivíduo além de mostrar que é um "bom homem", trabalhador, dedicado, entre outras qualidades, precisa mostrar-lhes a todo o momento que também que é confiável e que é merecedor do voto de confiança (SIQUEIRA; ROSTELATO, 2009).

Para Siqueira e Rostelato (2009, p. 117) "enfrentar os olhares preconceituosos e cismados com qualquer ato de deslize torna-se o principal obstáculo a ser enfrentado".

Para que haja um melhor entendimento do fenômeno da aceitação so- 
MARCADOS PELO CRIME: OS DESAFIOS ENFRENTADOS NO PROCESSO DE REINSERÇÃO SOCIAL DE PESSOAS QUE CUMPRIRAM PENA EM REGIME FECHADO

cial, é necessário entender também a Teoria das Representações Sociais, que Moscovici $(1976$, xiii) citado por Moscovici $(2015$, p. 21) aponta como

Um sistema de valores, ideias e práticas, com uma dupla função: primeiro, estabelecer uma ordem que possibilitará às pessoas orientar-se em seu mundo material e social e controlá-lo; e em segundo lugar, possibilitar que a comunicação seja possível entre os membros de uma comunidade, fornecendo-lhes um código para nomear e classificar, sem ambiguidade, os vários aspectos de seu mundo e da sua história individual e social.

Minayo (2003, p. 89) descreve que representações sociais "é um termo filosófico que significa a reprodução de uma percepção retida na lembrança ou no conteúdo do pensamento".

Para Alvez-Mazzoti (2008) é um conjunto de valores, construídas socialmente e fruto de interações sociais que explicam eventos, pessoas e/ou objetos. Dentro da Teoria das Representações Sociais há a objetivação e a ancoragem, onde a primeira transforma o abstrato em objeto e a segunda assimila este objeto a uma imagem comum. Ou seja, transforma o desconhecido em algo familiar (ALVEZ-MAZZOTI, 2008).

A partir desta teoria, pode-se obter melhor entendimento sobre o fenômeno da aceitação social que permeiam a pesquisa.

\section{Método de pesquisa}

\subsection{Delineamento da pesquisa}

A presente pesquisa é de natureza qualitativa, que é o tipo de pesquisa que se baseia na qualidade das informações obtidas, pois de acordo com o tema proposto torna-se necessário um aprofundamento a respeito do tema (GIL, 2010). Além disso, pode-se classificar também como uma pesquisa descritiva, que são pesquisas que descrevem um determinado fenômeno e "têm como objetivo estudar as características de um grupo" (GIL, 2010, p. 27).

\subsection{Participantes}

Foram entrevistados 6 (seis) sujeitos do sexo masculino, que se encontram em meio aberto e que já cumpriram a pena em regime fechado no sistema prisional do Estado do Espírito Santo. A escolha do sexo se deu apenas pelo fato de que a porcentagem da população carcerária masculina ser maior que a população feminina.

Os participantes foram buscados a partir da amostragem de acessibilidade ou conveniência do tipo não probabilística, que é o tipo de amostra na qual o pesquisador seleciona os elementos a quem tem acesso, de forma que esses 
elementos representem o universo que será pesquisado (GIL, 2010). Portanto, essa amostra foi concebida através de uma rede de contatos em que se obteve informações e indicações de pessoas que apresentavam características do perfil da pesquisa, que aceitaram conhecer seus objetivos e, posteriormente, avaliaram sua participação.

3.3 Instrumentos de coleta de dados

Os dados foram coletados através de entrevistas semiestruturadas que podem ser definidas como entrevistas que

Combinam perguntas abertas e fechadas, onde o informante tem a possibilidade de discorrer sobre o tema proposto. O pesquisador deve seguir um conjunto de questões previamente definidas, mas ele o faz em um contexto muito semelhante ao de uma conversa informal. O entrevistador deve ficar atento para dirigir, no momento que achar oportuno, a discussão para o assunto que o interessa fazendo perguntas adicionais para elucidar questões que não ficaram claras ou ajudar a recompor o contexto da entrevista, caso o informante tenha "fugido" ao tema ou tenha dificuldades com ele (BONI; QUARESMA, 2005, p. 3).

Além disso, foram registradas através de um gravador e, em seguida, transcritas para a análise dos dados obtidos.

\subsection{Aspectos éticos}

Todos os participantes tiveram acesso ao Termo de Consentimento Livre e Esclarecido, tendo em vista que esses não foram, sob nenhuma hipótese, identificados nos dados coletados, e que foram utilizados para fins acadêmicos. A participação ocorreu de forma voluntária e a integridade física, emocional e psicológica dos participantes foram resguardadas.

A desistência a qualquer momento da pesquisa foi permitida, sem qualquer dano ou coesão. A desistência não acarretou, tampouco acarretará riscos ou danos físicos aos participantes, sejam entrevistados ou entrevistador.

\subsection{Análise e interpretação dos dados}

Os dados foram analisados por meio da Análise de Conteúdo proposto por Bardin (2011, p. 50) na qual "A análise de conteúdo, por seu lado, visa conhecimento de variáveis de ordem psicológica, sociológica, histórica etc, por meio de um mecanismo de dedução com base em indicadores reconstruídos a partir de uma amostra de mensagens particulares".

Tomou-se ainda, como ponto de partida, a análise de respostas a questões abertas, que "trata-se de examinar as respostas a um inquérito que explora as relações psicológicas que o indivíduo mantém com o automóvel" (BARDIN, 2011, p. 66). 
MARCADOS PELO CRIME: OS DESAFIOS ENFRENTADOS NO PROCESSO DE REINSERÇÃO SOCIAL

A pesquisa contém um teor qualitativo, portanto, encontrou-se variáveis que foram, posteriormente, categorizadas por meio da Análise de Conteúdo. As categorias temáticas foram: Dados sociodemográficos; A família no processo de reinserção social; Vivências de violência; Vivências de preconceito; Estratégias de ressocialização e Perspectivas de futuro, todas produzidas a partir da análise de respostas dadas pelos participantes.

\section{Apresentação e discussão dos resultados}

Os resultados dos estudos foram organizados em seis subtítulos: Dados sociodemográficos; A família no processo de ressocialização; Vivências de violência; Vivência de preconceito; Estratégias de ressocialização e Perspectivas de futuro.

\subsection{Dados sociodemográficos}

A entrevista teve início com perguntas que auxiliaram no delineamento dos dados sociodemográficos dos participantes, tais como: idade, escolaridade, estado civil, quantidade de filhos, religião, o tempo em que cumpriram pena no regime fechado, o tempo que esses sujeitos se encontram em liberdade e o tipo de crime que cometeram.

O estudo foi composto por seis participantes do sexo masculino, cujos nomes foram trocados por nomes fictícios para preservar suas identidades. Além disso, possuem idades entre 23 e 37 anos.

Com relação à escolaridade, dois dos sujeitos cursaram até a $8^{\mathrm{a}}$ série do Ensino Fundamental, dois cursaram, respectivamente, $1^{\circ}$ e $2^{\circ}$ anos do Ensino Médio e outros dois cursaram o Ensino Médio completo.

De acordo com as declarações do estado civil dos participantes, dois deles vivem em união estável e os quatro restantes são solteiros.

No que diz respeito aos filhos, um dos participantes não possui, um tem apenas um filho, um tem dois filhos, dois possuem quatro filhos e um participante possui cinco filhos.

Quando perguntados sobre sua religião, apenas um dos sujeitos declarou não possuir nenhuma religião, enquanto os outros cinco se declararam evangélicos. Contudo, quando questionados se praticantes, apenas um respondeu afirmativamente.

O tempo de cumprimento de pena variou entre 4 meses e 4 quatro anos, sendo um que cumpriu aproximadamente 4 meses, e os cumprimentos dos outros participantes foram de 1 ano e 9 meses, 1 ano e 11 meses, 2 anos e 3 meses, 3 anos e 9 meses e, por último, um sujeito cumpriu pena por 4 anos.

Em relação à liberdade, o tempo variou entre 1 e 8 anos, sendo três sujeitos há aproximadamente 1 ano, um por volta de 2 anos em liberdade e um que se encontra livre há 8 anos. 
Questionados sobre o tipo de crime ao qual cometeram, dois deles foram enquadrados no artigo 33 da Lei $n^{\circ}$ 11.343/2006, caracterizado pelo tráfico de drogas (Brasil, 2006). Outros dois dos seis entrevistados foram reclusos pelo artigo 157, que consta no Código Penal (CP) como Roubo. Outro participante foi recluso pelo artigo 121 do CP que traduz homicídio simples e também responde pelo artigo 14, inciso 2, caracterizado pelo crime de Tentativa (Delmanto, 2017). Outro participante que cumpriu pena foi enquadrado no artigo 14 da lei 10.826/2003 conhecida como Estatuto do Desarmamento, sendo este artigo caracterizado por Porte ilegal de arma de fogo de uso permitido (BRASIL, 2003).

\subsection{A família no processo de reinserção social}

Segundo Cabral e Medeiros (2014, p.55) "a família é o ambiente primário no qual o indivíduo irá iniciar seu processo de desenvolvimento e socialização, isto é, onde, pela primeira vez, terá relações interindividuais e pessoais". Sendo assim, para o auxílio da verificação da participação familiar na vida dos participantes e conhecer o vínculo que se estabelece entre eles antes da reclusão, buscou-se analisar a reação da família ao ter conhecimento sobre a prisão dos sujeitos.

Três dos participantes classificaram as reações como abalados, como pode-se observar a seguir na fala de um deles: "Bem, ficaram muito abalados. Minha mãe, meu pai, ficaram muito abalados" (Thiago, 8 anos em liberdade). Um dos participantes classificou a reação como péssima, de um sofrimento grande e tristeza, como pode-se notar em seu relato: "A reação dela [mãe] foi péssima, ela ficou muito mal, ela chorou muito. E a cada visita que eu via, ela estava pior" (Gustavo, 2 anos em liberdade). Outro participante declarou que seus familiares ficaram surpresos, entretanto, já esperavam que pudesse ocorrer a prisão: "Ficaram surpresos alguns, outros já esperavam pela vida que eu estava levando" (Ricardo, 3 anos em liberdade). E por último, o participante restante resumiu a reação familiar em tristeza: "Tristeza né, muita tristeza" (Jhonas, 1 ano em liberdade).

Diante disso, pode-se observar que em relatos de todos os participantes, encontra-se presente o sofrimento da família ao ter conhecimento da prisão dos sujeitos.

Oliveira citado por Cabral e Medeiros (2014, p. 58) explica que

A família do condenado também sofre imensamente com a privação da liberdade de seu membro. A relação de interdependência dos elementos componentes da família faz com que a pena aplicada a um estenda seus efeitos a todos os outros, reorganizando, em diversos sentidos, o movimento dinâmico familiar. As consequências da punição no âmbito da família aparecem sob o ponto de vista psicológico, social e financeiro. 
MARCADOS PELO CRIME: OS DESAFIOS ENFRENTADOS NO PROCESSO DE REINSERÇÃO SOCIAL

Além da reação familiar, também foi perguntado aos sujeitos sobre a participação familiar no processo de ressocialização de acordo com suas percepções. Quatro dos participantes responderam que a família participa na forma de incentivo e/ou apoio: "Tenta ajudar de todas as formas né?! Busca [...] ajudar o máximo pra gente tá se reintegrando de novo [...] arrumar um trabalho e tal. Pra tentar [...] distrair a mente pra esquecer a vida passada. É importante porque senão a pessoa fica revoltada sem um apoio." (Jhonas, 1 ano em liberdade).

Um participante respondeu que a família participa $100 \%$ do processo de ressocialização: "Eu diria que é $100 \%$ a participação da minha família. Primeiramente a Deus né?! Mas de resto é $100 \%$ da minha mãe. É ela que me dá forças pra mim querer o melhor, pra tá aqui batalhando" (Gustavo, 2 anos em liberdade).

Outro participante apresentou que sua família auxilia com conselhos: "Eles me dão muito conselho pra [...] eu não ir na conversa dos outros. Pra mim seguir minha vida só, porque pra falar dos outros, é fácil, mas pra ajudar, é difícil" (Bernardo, 1 ano em liberdade).

Nota-se que diante das respostas obtidas, a família é um grupo social que está presente na vida dos sujeitos antes e depois do cárcere e essa presença não se submete a qualquer condição. Ou seja, diante da amostra analisada, verificou-se que as convivências não sofreram significativas alterações após o sujeito passar pelo sistema prisional, tampouco dependeu da reincidência ou ressocialização do indivíduo.

Para Bock, Furtado e Teixeira (2009), a família é uma instituição primária que auxilia no processo de reconstrução da identidade social após os indivíduos terem passado pelo cárcere e toda violência que ele possa vir a representar na vida destes.

Este suporte é importante para favorecer o desenvolvimento e bem-estar dos egressos do sistema prisional, assim como também auxilia na assimilação dos valores éticos e humanitários aos quais os indivíduos necessitarão para reinserir-se socialmente. Além disso, é um aporte afetivo e financeiro que facilita nesse processo (SANTOS, 2007).

\subsection{Vivências de violência}

Com relação à violência sofrida, nota-se que dos seis participantes, quatro declararam terem sofrido violência durante a prisão. Para Pequeno (2016, p.138) "a constante violação dos direitos fundamentais da pessoa humana, sob a forma de exclusão, perseguição, aniquilamento, é o símbolo maior do caráter bestial da violência no nosso tempo".

Ainda na visão do autor, aqueles que se propõem a seguir contra essa cultura violenta atual, seja indivíduo ou grupo, acabam por sofrer os danos que ela causa (PEQUENO, 2016). Quando questionado sobre a violência sofrida no ato da prisão Gustavo ( 2 anos em liberdade) relata que 
Hum... Com certeza! Nós sofremos violência verbal né?! Fomos agredidos verbalmente, lógico, até porque isso é normal né?! $\mathrm{Na}$ prisão, foi dois policiais da GOT [Grupo de Operações Táticas] que prenderam a gente, então levamos chute, coturno deles... inclusive o cara que foi preso junto comigo tomou um chute na boca que pocou a boca dele toda. Aí depois de nós agredidos lá, eles ainda permaneceram com a gente lá até esperar outra guarnição que não quis levar a gente porque estava acabando o plantão, aí outra guarnição que foi já uma caminhonete... aí essa aí pegou pra conduzir a gente, aí a mulher agrediu a gente de novo. Aí a gente deitado de cara no chão, ela agrediu a gente, deu um monte de chute na gente, enfim, fomos agredidos sim.

Nota-se uma naturalização da violência verbal, como se a dignidade humana não necessitasse de ser respeitada. E diante da violência física também sofrida, entende-se que os punidores, neste caso, seguem a lógica segregacionista de que se os indivíduos "escolheram" serem transgressores da norma social, devem sofrer a violência imposta, e por esse pensamento ser tão enraizado na sociedade, o transgressor também o toma para si, e acredita ser parte da abordagem policial tais atos, ou seja, temos a violência como resultado de um constructo social (SOUSA; BEZERRA, 2016).

Durante o cumprimento da pena, três participantes relatam violência e outros três informaram não terem sofrido nenhum tipo de violência.

Quando questionados sobre o tipo de violência sofrida, três dos participantes descreveram violência física "[...] Lá dentro eu apanhei. Tenho marca de borracha em mim. Lá é o presídio mais cruel do Espírito Santo, o presídio que o procedimento é rígido mesmo e lá você tem que aprender e se não aprender você entra no pau [...]" (Bernardo, 1 ano em liberdade).

Ainda que o processo punitivo tenha sofrido diversas modificações ao longo do tempo, o que se vê atualmente são resquícios dos suplícios do século XVIII, onde se tentava abolir a criminalidade por meio de um "circo de horrores" em praça pública. A pena, em dias atuais, se dá, ainda que ilegalmente, como o corpo como alvo principal (FOUCALT, 2002).

Em relação à violência sofrida após saírem da prisão, todos os seis participantes relataram não terem sofrido qualquer tipo de violência. Entretanto, embora alegue não ter sofrido nenhuma violência, a fala de Bernardo (1 ano em liberdade) chama a atenção

Depois que eu saí [...] eles tipo pergunta se eu quero voltar [...] se eu gostei de lá dentro num tem?! Igual a Força Tática me parou e puxou meu nome e viu o meu artigo pesado, homicídio e tentativa de homicídio, e eles falou (sic) assim: "É bichão, você sabe que quem mata morre também". Aí eu falei: "Rapaz, eu matei foi na minha legítima defesa, mas se for pra eu fazer um negócio desse hoje, eu vou pensar mil e duas vezes antes porque quem sofreu com isso foi eu e minha família e meus filhos [...]. 
MARCADOS PELO CRIME: OS DESAFIOS ENFRENTADOS NO PROCESSO DE REINSERÇÃO SOCIAL

Nota-se na abordagem policial um preconceito sobre o sujeito que cometeu um homicídio no passado, sendo que a fala vai além dos procedimentos padrões da corporação.

Com isso, observa-se, a partir da amostra analisada, que há presença da violência tida como cultural nos relatos. Nestes casos, a agressão provém de uma sociedade dominante e que faz com que os sujeitos naturalizem e as aceitem. Como consequência disto, pode-se haver a perpetuação dessa cultura violenta por parte do indivíduo para com aqueles que o cercam (SOUZA, 2008).

\subsection{Vivências de preconceito}

Após a liberdade, cinco dos seis participantes afirmaram terem sofrido preconceito. Apenas um afirmou negativamente.

O preconceito é uma ideia pré-concebida que direciona um comportamento negativo e/ou atitude a determinado indivíduo ou grupo social (RODRIGUES; ASSMAR; JABLONSKI, 2001).

Quando o sujeito tem sua liberdade decretada, já vem com uma determinada "formação no crime" devido aos diversos contatos com diferentes transgressores na prisão. Com isso, o preconceito vivido fora do cárcere só agrava a situação de ineficácia da ressocialização e aumentam as chances de reincidência (NOBRE; PEIXOTO, 2015).

Sobre as vivências de preconceito, três participantes responderam que sofreram discriminação para obter emprego "[...] Por causa de você já ter passagem, as pessoas te vê discriminando entendeu?! Coisa que você vai cometer um crime ali dentro ou sei lá, pode querer roubar a empresa, [Por] causa disso. " (Thiago, 8 anos em liberdade).

Nota-se na fala citada que, no retorno à sociedade, o convívio pode ser um tanto complicado, pois além de mostrar a todo o momento que é um "bom homem" o sujeito precisa deixar claro também que merece o voto de confiança de quem os auxilia (SIQUEIRA; ROSTELATO, 2009).

Para Gustavo (2 anos em liberdade) o preconceito vivenciado foi

As pessoas me julgarem sem nem me conhecer sabe, só saber meu nome e já ter um rio de coisas pra falar de mim. Coisas ruins... Que eu faço isso, faço aquilo outro, que eu sou... enfim, fala de mim como se me conhecessem e não me conhecem. Só pelo fato de saber disso, da minha história [na prisão].

Observa-se na fala acima uma estereotipagem do sujeito com base no fato deste ter sido recluso. O estereótipo, tido como sua base do preconceito, são formas "classificar" as pessoas de maneira pouco reflexiva e equivocada (RODRIGUES; ASSMAR; JABLONSKI, 2001).

A invisibilidade social, outra face do preconceito que de acordo com Uhlein (s/d), vem a ser a presença do indivíduo no ambiente, porém este passa 
despercebido ou ainda que queira, não faz parte do todo, esteve presente nos relatos conforme traz Jhonas ( 1 ano em liberdade) "Muito. Muito preconceito. [...] da pessoa não olhar mais na sua cara, que te conhece há muito tempo não olhar mais pra você. [...] As pessoas olham você com outro olhar já, tipo: "o cara perigoso, o cara que tem medo, que sente [...] coisas chatas né?!"

Com isso, remete-se a reflexão do quanto os sujeitos precisam, de certa forma, provar que realmente se ressocializou e reforça ainda os relatos de quem já sofreu o preconceito explícito de que eles precisam, a todo o momento, mostrar a sociedade que merecem a confiança que podem vir a ser depositadas, como esses sujeitos não fossem dignos dela (SIQUEIRA; ROSTELATO, 2009).

Alguém que tenha cumprido pena para sociedade, na visão dos entrevistados, tem que aprender a conviver com o preconceito e julgamento social, pois estes se tornam constantes na vida deles. É como se trouxessem consigo dessa experiência uma marca irreparável de criminoso.

A inserção no trabalho se torna ainda mais difícil quando o sujeito cumpriu pena para dois dos entrevistados

Por causa que as pessoas te vê [...] com discriminação entendeu?! Não confia muito, [...] já acha que você vai cometer alguma infração ali dentro. Aí foi bem difícil conseguir esse emprego. [...] eu trabalho por conta própria, pq se fosse pros outros, acho que até hoje não tinha conseguido emprego não (Thiago, 8 anos em liberdade).

E mesmo quem conseguiu retornar ao mercado de trabalho como empregado encontrou no encaminhamento uma saída para essa busca complicada. "Então, só consegui porque fui lá na Assistente Social onde eu assino [Secretaria de Estado da Justiça] e pedi eles pra me ajudar porque eu não tava conseguindo arrumar não. Aí ela me deu uma carta de encaminhamento pra essa empresa que eu trabalho agora" (Ricardo, 3 anos em liberdade).

Já para Jhonas, mesmo após um ano que se encontra em liberdade, ainda não conseguiu sair da situação de desemprego. Isto se dá por diversos fatores (econômicos, políticos, entre outros). Contudo, o fator mais explícito para os participantes se dá à percepção que a sociedade tem do indivíduo que tenha passado pela prisão.

Quando questionados sobre esta percepção, três deles classificaram como monstros conforme aparece na fala de Gustavo ( 2 anos em liberdade)

Olha de uma maneira geral na minha percepção, as pessoas que já cumpriram pena são vistas como monstros pela sociedade. São vistas como monstros sabe?! A sociedade em si, a maioria, porque toda regra tem excessão, não acredita nisso, nesse lance de ressocialização, regeneração. Num (sic) tem aquele ditado, pau que nasce torto morre torto?! Por um erro de alguém as pessoas julgam ela por aquele erro pelo resto da vida dela. Então na minha percepção, de um modo geral, a sociedade nunca 
MARCADOS PELO CRIME: OS DESAFIOS ENFRENTADOS NO PROCESSO DE REINSERÇÃO SOCIAL

perdoa. A justiça pode perdoar um crime e acreditar que alguém possa ser ressocializado, mas infelizmente a sociedade não vê dessa forma e não acredita nisso, a sociedade só sabe julgar e pra eles quem já cumpriu pena não tem solução nunca né?! Eles falam bem assim "Pau que nasce torto, morre torto" e "Vagabundo não para, dá um tempo".

A Teoria das Representações Sociais apresentada por Moscovici, em 1961, pode explicar esse fenômeno da ligação do sujeito que cumpriu pena com a imagem do monstro. A representação social é um conjunto de valores que se resultam de uma interação social. Dentro deste conceito existem a objetivação que transformam os conceitos em imagens e a ancoragem que faz a ligação do objeto com uma representação social que já existe, ou seja, aproxima o objeto com algo comum (ALVEZ-MAZZOTI, 2008).

Portanto, a necessidade de classificar esses sujeitos parte do princípio de que se eles estão cumprindo pena, não estão preparados para o convívio social, logo são monstros. Entretanto, é necessário entender que são seres humanos passíveis de erros e acertos, e se errou e já cumpriu a pena, teoricamente foi reeducado para este convívio. Neste ponto que entra a discussão sobre as falhas nos deveres do Estado em garantir o princípio de dignidade da pessoa humana, citada no artigo $38 \mathrm{do} \mathrm{CP}$, em que diz "O preso conserva todos os direitos não atingidos pela perda da liberdade, impondo-se a todas as autoridades o respeito à sua integridade física e moral" e o objetivo principal da ressocialização que é o de readequar às normas sociais através do cumprimento da pena (SANTOS; SOUZA, 2013).

Thiago (8 anos em liberdade) classificou a visão social sobre quem cumpriu pena como pessoa que "não tem mais jeito". Quando questionado sobre como ele acredita que a sociedade vê as pessoas que passaram pelo sistema prisional, ele responde: "Ah, com muita discriminação, muita... muito preconceito entendeu?! São muito julgadas. Porque acha que a pessoa não muda, que a pessoa não tem mais jeito [...]".

Já para Ricardo (3 anos em liberdade) isso depende de quem vai lidar com eles, pois, em sua percepção, uns ajudam enquanto outros discriminam, ou seja, não é uma regra.

Ah, alguns dá uma ajuda, alguns já discriminam. Já trabalhei em lugar já que a pessoa falou: - "Não, todo mundo tem uma segunda chance, você vai continuar trabalhando comigo, independente do que você fez" e me aceitou, mas tem uns que já não pensam a mesma coisa né?!

Pensando nisso, os participantes foram questionados sobre o motivo de alguns indivíduos saírem da prisão e não cometerem mais crimes, enquanto outros continuam associados à criminalidade. 


\subsection{Estratégias de ressocialização}

De acordo com o questionamento levantado anteriormente, as respostas demonstraram que cinco dos seis participantes não souberam falar sobre o porquê de indivíduos não cometerem mais crimes, responderam apenas o porquê de continuarem na criminalidade. Dentre estes cinco, dois relacionaram à falta de oportunidades.

[...] Falta de oportunidades entendeu?! Porque ela sai dali da prisão já sai com uma mão na frente outra atrás... porque quando você vai preso perde tudo que tem na rua, se tiver alguma coisa ainda. Aí quando sai, sem ninguém pra poder dar uma oportunidade pra ela, aí como é que ela vai voltar pra sociedade de novo? Aí fica muito difícil entendeu (THIAGO, 8 anos em liberdade)

O apenado encontra diversos fatores que dificultam a sua reintegração social. Alves (2018) indica a superlotação nos presídios como fortes indicadores para o egresso retornar à vida do crime. O processo de ressocialização tem como finalidade que a cultura da criminalidade seja superada, isto é, o apenado deve buscar sua reinserção social e reestruturação da personalidade através das oportunidades que lhe são ofertadas. Se isto lhe falta, as chances de reincidência criminal são potencializadas (BRAGA, 2014).

Por outro lado, se as oportunidades ofertadas e referência de sucesso para o sujeito for o crime, as chances da reincidência podem se tornar altas. Para Ricardo (3 anos em liberdade) esta reincidência é relacionada à convivência e oportunidades, para o participante o indivíduo volta a praticar crimes “Porque quem continua, não se afastou das más companhias, das antigas companhias. Porque se você ficar perto, vai precisar de um dinheiro, vai acontecer um problema e as oportunidades [do crime] vêm toda hora".

Além disto, há quem encontra, na perpetuação da vida do crime, uma estratégia de sobrevivência. "Porque tem muita pessoa, como vou dizer?! Tem pessoas que são donas de boca de fumo, por exemplo, se eles não matar, vão morrer. Então prefere matar e não morrer, aí fica lá dentro mais uns nove anos, mas não morrer" (BERNARDO, 1 ano em liberdade).

Já para Gustavo (2 anos em liberdade), a ressocialização está relacionada ao caráter do sujeito "Isso aí na minha opinião, eu penso que é questão de caráter, de índole mesmo [...]".

A análise desta resposta remete-se ao estudo do comportamento antissocial, em que (Rodrigues, Assmar e Jablonski, 2002) explicam que a agressão é um conceito bem mais amplo do que o que se conhece no senso comum. Ele diz respeito a todo e qualquer comportamento que possua, em sua finalidade, causar danos físicos ou psicológicos a alguém ou a um objeto, e que esse comportamento não se limita ao ser humano. Há controvérsias entre autores entre ser algo inato ou aprendido. Ou seja, seguindo a visão do participante, alguém 
MARCADOS PELO CRIME: OS DESAFIOS ENFRENTADOS NO PROCESSO DE REINSERÇÃO SOCIAL DE PESSOAS QUE CUMPRIRAM PENA EM REGIME FECHADO

que reincide criminalmente é um indivíduo que pode vir a possuir um comportamento agressivo. Entretanto, ressalta-se que a visão trazida pelo entrevistado não encontra consonância com a literatura contemporânea sobre violência e criminalidade. Tal visão também é partilhada pelos autores do presente estudo.

Apesar do teor negativo das respostas relacionadas à ressocialização, foi questionado aos participantes sobre a perspectiva de futuro que eles haviam construído para a vida deles.

\subsection{Perspectivas de futuro}

Diante das respostas sobre o futuro, os seis participantes mencionaram melhorias, conforme demonstra a fala de Thiago (8 anos em liberdade) "Ai eu penso num futuro bom, quero que seja tranquilo... seja honesto, na paz, porque eu não quero saber de crime mais não [...]".

Dois citaram estudos como forma de prosseguir a vida. Gustavo ( 2 anos em liberdade) aponta na entrevista que

Com toda sinceridade desse mundo minha maior expectativa é provar pra mim mesmo que sou capaz de passar por tudo que já passei. De cabeça erguida e andar com minhas próprias pernas e me formar. É que eu também tenho esse sonho de me formar. Ir além. De mostrar pra mim mesmo que sou capaz, porque eu sei que sou! Sei do meu potencial.

Apesar de não poder basear-se apenas no grau de instrução do sujeito, este é um importante benefício para o bom desempenho do processo de ressocialização. Além disso, indica também que o resgate da autoestima e dignidade como procedimentos de aplicabilidade para auxílio deste processo (SILVA, 2018).

Dois dos seis entrevistados demonstraram o desejo de melhoria de futuro através do emprego. "Meu futuro agora é cada vez melhorar na empresa lá. Meu patrão me dando um cargo melhor agora e bola pra frente" (Manoel, 1 ano em liberdade).

Os três pilares que norteiam a reinserção do sujeito são: educação, capacitação e trabalho (Silva, 2018). Para Foucault (2002) o trabalho é a chave para transformação do sujeito e deve ser uma forma de aprender e obter pecúlio.

Além disso, a aceitação social é indispensável nesse processo, pois é nela que o sujeito encontra apoio para reconstruir sua identidade social, bem como ir contra olhares e comentários preconceituosos.

[...] eu quero é viver uma nova vida com a sociedade, ser digno e onde eu andar, todo mundo me respeitar. Me ver com outro olho. Não é porque eu sou ex-presidiário que as pessoas vão ter medo de mim pelo artigo que eu tive. Não tem que ter medo, tem que ter confiança e respeito e eu dar respeito a pessoa também (BERNARDO, 1 ano em liberdade). 
Acredita-se que a mudança de visão da sociedade é um fator primordial para que as perspectivas de futuro elencadas consigam se concretizar nas trajetórias de vida dos entrevistados.

\section{Considerações Finais}

Ao analisar os resultados, verificou-se que os desafios que dificultam o processo de reinserção social de pessoas que cumpriram pena em regime fechado como: a violência física sofrida no ato da prisão e dentro dela; os preconceitos sofridos após a liberdade tais como estereotipagem, segregação, invisibilidade social; além da falta de oportunidades na vida fora do crime, em contrapartida com oportunidades mais rentáveis no crime.

Também se nota que há uma perspectiva de melhorias para o futuro por parte dos participantes e o desejo de se afastarem da criminalidade. E as respostas apontaram ainda a família como principal grupo social que apoia, incentiva, mantém presença constante e aconselha essas pessoas a seguirem fora da vida do crime, almejando o sucesso do processo de reinserção social.

Com o estudo entende-se que quando alguém transgride uma lei, teoricamente, o curso de sua trajetória de responsabilização deveria ser o cumprimento da pena perante a justiça e, concomitantemente, a reeducação para o retorno à sociedade. Esta deveria o receber de forma acolhedora e com oportunidades para que o sujeito não se sinta um excluído e tenha as chances minimizadas quanto à reincidência criminal.

No entanto, conforme mostra o estudo, a prática difere-se da teoria, sobretudo, em dois aspectos: quando o Estado falha no que diz respeito a ressocializar o indivíduo e zelar para que haja condições mínimas dos princípios da dignidade humana no cumprimento da pena; e quando o sujeito retoma o convívio social e é estigmatizado, segregado e alvo de desconfianças por parte da sociedade.

Conclui-se que há a necessidade de mudanças na cultura da criminalidade. Torna-se necessário que a sociedade entenda que esse indivíduo é alguém que está cumprindo sua pena, está sendo responsabilizado pelo seu crime, e em algum momento retornará à sociedade. Sendo assim, não é de interesse de ambos que este retorno seja com alguém que, além de não ter reaprendido as normas morais e valores sociais, tenha uma "formação" a mais no crime, o que o tornaria um potencial reincidente.

Boas estratégias de ressocialização por vias de políticas públicas e a diminuição dos desafios para essa busca por parte da sociedade não são conivência com o crime, mas justamente o contrário, ou seja, a chance que o sujeito encontra para que não tenha que recorrer a reincidência. 
MARCADOS PELO CRIME: OS DESAFIOS ENFRENTADOS NO PROCESSO DE REINSERÇÃO SOCIAL

DE PESSOAS QUE CUMPRIRAM PENA EM REGIME FECHADO

\section{Referências}

ÁlVARO, José Luis; GARRIDO, Alicia. Psicologia social: perspectivas psicológicas e sociológicas. São Paulo: Mc Graw-Hill, 2006. 414 p.

ALVES, Rodrigo Costa. Estratégias da ressocialização como garantia dos direitos humanos pelo estado. Goiânia, 2018. Monografia do Curso de Formação de Praças de PMGO. Academia de Polícia Militar de Goiás.

ALVEZ-MAZZOTTI, Alda Judith. Representações Sociais: Aspectos teóricos e aplicações à educação. Revista Múltiplas Leituras. Brasília, v.1, n.1, p. 18-43, jan/jun. 2008.

BARCINSKI, Mariana; CÚNICO, Sabrina Daiana. Os efeitos (in)visibilizadores do cárcere: as contradições do sistema prisional. Rio Grande do Sul: Revista PSICOLOGIA, 2014, Vol. 28 (2), 63-70.

BARDIN, Laurence. Análise de Conteúdo. Lisboa: Edições 70, 2011. 279 p.

BRAGA, Ana Gabriela Mendes. Reintegração Social e as funções da pena na contemporaneidade. São Paulo: Revista Brasileira de Ciências Criminais, 2014. vol. 107/2014. p. 339-356.

BRASIL. Lei 10.826/2003 - Estatuto do Desarmamento. Disponível em: http://www.planalto.gov.br/ccivil_03/ LEIS/2003/L10.826.htm . Acesso em: 29 out. 2018.

BRASIL. Lei 11.343/2006 - Lei das Drogras. Sistema Nacional de Políticas Públicas sobre Drogas. Disponível em: http://www.planalto.gov.br/ccivil_03/_ato2004-2006/2006/lei/l11343.htm . Acesso em: 29 out. 2018.

BOCK, Ana Mercês Bahia; FURTADO, Odair; TEIXEIRA, Maria de Lourdes Trassi. Psicologias: uma introdução ao estudo de psicologia.14 ed. São Paulo: Saraiva, 2009. 368 p.

BONI, Valdete; QUARESMA, Sílvia Jurema. Aprendendo a entrevistar: como fazer entrevistas em Ciências Sociais. Em Tese, v. 2, n. 1, p. 68-80, 2005.

CABRAL, Yasmin Tomaz; MEDEIROS, Bruna Agra de. A família do preso: efeitos da punição sobre a unidade familiar. Transgressões, Cidade, v.2, n.1, p. 50-71, mai. 2014.

DELMANTO, Celso. CóDIGO penal comentado: 9 ed.. 9 ed. São Paulo: Saraiva, 2017. 1096 p.

FOUCAULT, Michel. Vigiar e punir: história da violência nas prisões. 27 ed. Petrópolis: Vozes, 2003. 262 p.

GIL, Antônio Carlos. Como elaborar Projetos de Pesquisa. 5 ed. São Paulo: Atlas, 2010. 184 p.

MADEIRA, L, 2004. A atuação da sociedade civil na ressocialização de regressos do sistema penitenciário. In: CONGRESSO LUSO-AFRO-BRASILEIRO DE CIÊNCIAS SOCIAIS

COIMBRA, VIII, Coimbra, 2004. 20 p.

MICHAUD, Yves. A violência. São Paulo: Ática, 1989.120 p.

MINAYO, Maria Cecília de Souza. O conceito de Representações Sociais dentro da Sociologia Clássica. In: GUARESKI, Pedrinho Arcides; JOVCHELOVITCH, Sandra. (Orgs.) Textos em Representações Sociais. 8 ed. Petrópolis: Vozes, 2003. 324 p.

MOSCOVICl, Serge. Representações sociais: investigações em psicologia social. 11 ed.. Petrópolis: Vozes, 2015. $404 \mathrm{p}$.

NOBRE, Bárbara Paula Resende; PEIXOTO, Aimê Fonseca. Análise da "ressocialização" penal brasileira. Revista Transgressões, v. 2, n. 1, p. 112-123, 2015.

OLIVEIRA, N. et al. Sistema penal brasileiro: Ressocialização ou reajustamento? In: SEMINÁRIO CIENTíFICO DA FACIG, Manhuaçu, p. 1-8, 2017.

PEQUENO, Marconi. Violência e Direitos Humanos. Revista Filosofia, Aurora, Curitiba, v. 28, n. 43, p. 135-146, jan./ abr. 2016.

SANTOS, Fernanda Valéria Gomes dos. Família: peça fundamental na ressocialização de adolescentes em conflito com a lei? Recife, 2007. Dissertação (Mestrado em Psicologia Clínica) - Universidade Católica de Pernambuco.

SANTOS, Taysa Silva; SOUZA, Simone Brandão. Da condição de "ressocialização" dos egressos do sistema prisional. Café com Sociologia. 2(3), 25-35, 2013. 
SEQUEIRA, Vânia Conselheiro. Vidas abandonadas: crime, violência e prisão. São Paulo: Educ: FAPESP, 2011.168 p.

SIQUEIRA, Dirceu Pereira; ROSTELATO, Telma Aparecida. Inclusão social dos ex-detentos: A alegria do retorno à sociedade versus a dificuldade de ressocialização. Paraná: Revista do Programa de Mestrado em Ciência Jurídica da Fundinopi, 2009. 111-123 p.

SOUSA, Luiza Eridan Elmiro Martins de; BEZERRA, Anna Paula Fagundes. Direitos humanos e juventude: representações da adolescência em conflito com a lei no brasil. Revista Sociais e Humanas, v. 30, n. 3, 2017.

SOUZA, Mirian Rodrigues. Violência nas escolas: causas e consequências. 2008. Disponível em: <http:// www.unifan.edu.br/files/pesquisa/Artigo\%20VIOL\%C3\%8ANCIA\%20NAS\%20ESCOLAS\%20-\%20 CAUSAS\%20E\%20CONSEQU\%C3\%8ANCIAS.pdf> . Acesso em: 05 nov. 2018.

SILVA, Fernando Ferreira. A ressocialização de presos no sistema carcerário brasileiro. Goiânia, 2018. Monografia do Curso de Formação de Praças de PMGO. Academia de Polícia Militar de Goiás.

RODRIGUES, Aroldo; ASSMAR, Eveline Maria Leal; JABLONSKI, Bernardo. Psicologia social. 20 ed. Petrópolis: Vozes, 2001. 478 p.

UHLEIN, Tânia. Invisibilidade social e a questão da criminalidade entre os jovens brasileiros. Seminário intermunicipal de pesquisa, v. 15, p. 1-24. 